\title{
Impact of Obesity on Anti-Mullerian Hormone (AMH) Levels in Women of Reproductive Age
}

\author{
Alexis L. Oldfield ${ }^{1}\left(\mathbb{D}\right.$, Maryam Kazemi $^{2}\left(\mathbb{1}\right.$ and Marla E. Lujan ${ }^{2, *}$ \\ 1 Biomedical and Biological Sciences, Cornell University, Ithaca, NY 14853, USA; alo49@cornell.edu \\ 2 Division of Nutritional Sciences, Cornell University, Ithaca, NY 14853, USA; maryam.kazemi@cornell.edu \\ * Correspondence: marla.lujan@cornell.edu; Tel.: +1-607-255-3153
}

Citation: Oldfield, A.L.; Kazemi, M.; Lujan, M.E. Impact of Obesity on Anti-Mullerian Hormone (AMH) Levels in Women of Reproductive Age. J. Clin. Med. 2021, 10, 3192. https://doi.org/10.3390/jcm10143192

Academic Editor: Johannes Ott

Received: 7 July 2021

Accepted: 18 July 2021

Published: 20 July 2021

Publisher's Note: MDPI stays neutral with regard to jurisdictional claims in published maps and institutional affiliations.

Copyright: (c) 2021 by the authors. Licensee MDPI, Basel, Switzerland. This article is an open access article distributed under the terms and conditions of the Creative Commons Attribution (CC BY) license (https:// creativecommons.org/licenses/by/ $4.0 /)$.

\begin{abstract}
Obesity negatively impacts reproductive health, including ovarian function. Obesity has been posited to alter Anti-Müllerian hormone (AMH) production. Understanding biological factors that could impact AMH levels is necessary given the increasing use of AMH for predicting reproductive health outcomes in response to controlled ovarian stimulation, diagnosing ovulatory disorders, onset of menopause, and natural conception. In this narrative review, we evaluated the impact of obesity on AMH levels in healthy, regularly cycling reproductive-age women (18-48 years). Thirteen studies ( $n=1214$ women; $\left(811\right.$, non-obese (body mass index; BMI $<30 \mathrm{~kg} / \mathrm{m}^{2}$ ); 403, obese $\left.\left(\mathrm{BMI}>30 \mathrm{~kg} / \mathrm{m}^{2}\right)\right)$ ) were included, of which five reported decreased AMH levels with obesity, whereas eight showed comparable AMH levels between groups. Inclusion of women with higher obesity classes (Class 3 versus Class 1) may have been a factor in studies reporting lower AMH levels. Together, studies reporting AMH levels in otherwise healthy women remain limited by small sample sizes, cross-sectional designs, and lack of representation across the entire adiposity spectrum. Ultimately, the degree to which obesity may negatively impact AMH levels, and possibly ovarian reserve, in otherwise healthy women with regular menstrual cycles should be deemed uncertain at this time. This conclusion is prudent considering that the biological basis for an impact of obesity on AMH production is unknown.
\end{abstract}

Keywords: obesity; Anti-Müllerian hormone; ovary; body mass index; menstrual cycle

\section{Introduction}

Obesity remains a persistent and growing public health concern, with current rates nearing $40 \%$ of reproductive-aged women in the United States [1]. Obesity impacts a broad array of health risks in women across the lifespan [2], including adverse reproductive health outcomes such as menstrual cycle irregularity, abnormal uterine bleeding, endometrial hyperplasia, infertility, and pregnancy complications [3-7]. Furthermore, women with obesity are $20 \%$ more likely to experience later onset of menopause, which in part may underlie the increased risk of breast, ovarian, and uterine cancer seen in this population [8]. While the impact of obesity on reproductive health is known to be multi-factorial, many of the adverse reproductive outcomes may be linked to endocrine disruptions that reflect an impaired ovarian function [9]. Specifically, infertility observed in women with obesity is commonly associated with ovulatory disturbances and irregular menstrual cyclicity [10]. However, even women with obesity and regular menstrual cycles exhibit a longer time to spontaneous pregnancy [11-14] and lower success rates of controlled ovarian hyperstimulation compared to their normal-weight counterparts [15]. This potential for subfertility aligns with previous reports of an altered reproductive hormone profile in women with obesity and regular cycles including, decreased follicle stimulating hormone (FSH) levels [16], decreased luteinizing hormone (LH) pulse amplitude [17], increased estradiol levels [16], and decreased luteal phase progesterone production [17]. Despite strides toward characterizing the nature of reproductive disturbances in obesity, several questions remain to be answered on how and why obesity may drive disordered ovarian function. 
To that end, an altered ovarian follicular environment has been confirmed in women with obesity and involves disruptions in multiple systems, including steroidogenic action, metabolism, and inflammation, all of which can impact folliculogenesis and ovulatory potential [18]. The degree to which obesity impacts ovarian reserve is more controversial as available data have largely focused on sub- or infertile populations, wherein studies have not shown consistent associations between serum markers of ovarian reserve and body mass index (BMI) [4,19]. Anti-Mullerian hormone (AMH), a glycoprotein primarily produced by the granulosa cells of primary and early-stage antral follicles, is a marker whose association with obesity is controversial [20-22] - albeit a single meta-analysis suggests a negative association of AMH with BMI [19]. A growing interest in the use of $\mathrm{AMH}$ to predict reproductive health outcomes related to response to controlled ovarian stimulation [23], diagnosis of ovulatory disorders [24], the onset of menopause [25], and even natural conception [26] necessitate an understanding of biological factors, such as obesity, that could impact the predictive power of AMH for such reproductive outcomes.

The mechanisms through which obesity may adversely affect AMH production are unknown, but it has also been shown that with increasing adiposity, AMH production per antral follicle is reduced [27]. One possibility relates to an altered metabolic regulation of ovarian granulosa cells. Obesity is commonly associated with systemic insulin resistance and compensatory hyperinsulinemia. Excessive insulin levels have been shown to alter granulosa cell receptivity, and subsequently, AMH production [28]. Likewise, the increased leptin production associated with obesity could directly suppress AMH production. This observation is derived from the inhibitory effects of leptin administration on AMH and $\mathrm{AMH}$ receptor gene expression in cultured granulosa cells from patients undergoing controlled ovarian hyperstimulation [29]. More indirect in nature is the notion that lower $\mathrm{AMH}$ levels in women with obesity may result from a hemodilution effect of increasing body size [27]. Another possibility includes an impact of obesity on AMH catabolism and excretion. Obesity is known to alter the excretion of other reproductive hormones such as FSH, estradiol, and progesterone [17]. However, the exact mechanisms of AMH excretion are unknown [30]. Last, obesity may have an increased apoptotic effect at the ovarian follicle level, which is a mechanism observed in animal models [31]. While this posited mechanism may explain a reduced ovarian follicle pool and AMH levels, it seems less likely based on existing data of a later time to ovarian senescence in women with obesity.

Our current demographic necessitates further consideration of the impact of obesity on $\mathrm{AMH}$ production in healthy women of reproductive age. Most of the available data on $\mathrm{AMH}$ levels have been focused on women with infertility and/or polycystic ovary syndrome (PCOS) $[32,33]$. Of the data available in otherwise healthy women, AMH levels have been more commonly reported in women of lean BMI or women of advanced reproductive age $[34,35]$. Some women with obesity have regular cycles, yet their reproductive hormone profile suggests some level of ovarian dysfunction that could manifest as disordered AMH production compared to their lean counterparts [11]. Differences in AMH production across the adiposity spectrum could lead to inaccurate conclusions about the ability of AMH to adequately inform reproductive health outcomes in women. To address the current knowledge gap, we conducted a review to provide an up-to-date account of $\mathrm{AMH}$ levels in obese and non-obese women with regular menstrual cycles with the goal of establishing the degree to which obesity impacts AMH production in healthy, potentially fertile women.

\section{Methods}

This work represents a narrative review. The methods have been summarized herein.

\subsection{Review Question}

The PEO (Population (P), Exposure (E), Outcome $(\mathrm{O})$ ) criteria of our review were defined before the literature search. To that end, our study question was, in non-obese and 
obese regularly cycling women $(\mathrm{P})$, are AMH levels $(\mathrm{O})$ lower in reproductive age women with obesity and regular menstrual cycles compared to their non-obese counterparts (E)?

\subsection{Primary Outcome}

Our primary outcome was serum AMH levels.

\subsection{Data Sources and Search Strategy}

A search of published literature was conducted in the electronic databases of MEDLINE (PubMed), Institute for Scientific Information (ISI) Web of Science, and Scopus through 27 July 2020, using a search strategy based on the PEO framework, as described above. In short, studies included for review were limited to original research articles in which (1) the study was conducted in healthy, reproductive-aged (18-48 years) regularly cycling women, (2) the exposure was obesity, and (3) AMH levels were reported as an outcome for non-obese and obese groups. Only articles published in English were included. Studies must have used BMI as a categorical term, with obesity defined as a $\mathrm{BMI}>30 \mathrm{~kg} / \mathrm{m}^{2}$ and non-obese defined as some value $<30 \mathrm{~kg} / \mathrm{m}^{2}$. Where AMH levels were reported separately for overweight women (BMI $>25$ and $<30 \mathrm{~kg} / \mathrm{m}^{2}$ ), data were pooled with non-obese women where possible. Every record retrieved by this search strategy underwent a title and abstract screening to confirm that it aligned with the inclusion criteria. Articles that were relevant and appropriate were downloaded for full-text review, and data on the general characteristics of the study, patient population, study design, obesity definitions, AMH levels, and inclusion and exclusion criteria were extracted.

\subsection{Inclusion and Exclusion Criteria}

Briefly, observational (cross-sectional, case-control, cohort) studies or cross-sectional analysis of baseline measures from randomized controlled trials on women with regular menstrual cycles were included wherein the influence of obesity (non-obese and obese subtypes) as an exposure variable was evaluated on our study outcomes of interest. Nonpeer-reviewed studies; studies without the design of interest; studies wherein our outcomes of interest were not compared between non-obese and obese women with regular cycles; studies that were not conducted on healthy women; studies in women with PCOS and women who had single isolated features of PCOS (hyperandrogenism, oligo- or amenorrhea, and polycystic ovarian morphology); studies featuring children ( $<17$ years), pregnant women, or menopausal-aged women ( $>48$ years); and, where study data were irretrievable after contacting their corresponding authors were excluded.

\subsection{Data Extraction}

The following data were extracted using a standardized protocol: (1) first author's name; (2) study publication year; (3) participants' characteristics, including total sample size and the sample size of participants in the non-obese and obese groups; (4) study design and setting and type of data analysis/collection (prospective/retrospective); (5) participants' age; (6) participants' body mass index (BMI); and (7) AMH levels.

\section{Results}

\subsection{Literature Screening}

One thousand nine hundred fifty-six studies were identified using the search strategy through electronic databases. Duplicates found using multiple databases, keywords, and sources were removed $(n=985)$. The titles and/or abstracts of the remaining records ( $n=971$ ) were screened, of which 615 studies were deemed irrelevant. The full texts of the remaining 356 studies were assessed for eligibility. Of these, 329 were further excluded due to the full text not being available $(n=7)$, study design not being appropriate $(n=105)$, no comparison between obese and non-obese women $(n=150)$, study not performed on reproductive-aged women $(n=51)$, AMH not reported as an outcome $(n=13)$, and duplicate reports of the same study data $(n=3)$. Twenty-seven studies remained, and 
14 studies were further excluded due to an inconsistent definition of obesity. Ultimately, 13 studies were included in the review. A description of each study and its relevant characteristics and findings are summarized in Table 1.

\subsection{Study Characteristics}

Of the 13 studies identified in this review, eight involving a total of 193 obese and 261 non-obese women with regular menstrual cycles documented no significant differences in AMH levels between groups. Percent differences in AMH levels between groups ranged from $-70.4 \%$ to $62.5 \%$ (Mean: $-5.5 \%$; Median: $2.5 \%$ ). BMI of the non-obese participants ranged from 21.6 to $25.6 \mathrm{~kg} / \mathrm{m}^{2}$, and BMI of the obese participants ranged from 31.7 to $34.3 \mathrm{~kg} / \mathrm{m}^{2}$, which is consistent with the inclusion of women with strictly Class 1 (30 to $<35 \mathrm{~kg} / \mathrm{m}^{2}$ ) obesity. Studies were conducted across a broad array of countries and included diverse ethnic populations from North America [36,37], South America [38], Asia [39-41], and Africa [42,43]. Participants ranged in age from 23.8 to 46.2 years, with the mean age across studies being approximately 29 years. Studies were largely cross-sectional in nature and involved an assessment of serum AMH levels at a single time point during the menstrual cycle. The timing of the AMH assessment was not standardized to a particular stage of the cycle for all studies. However, six [38,40,42,44-47] of the 13 studies did measure AMH during the earliest part of the follicular phase (days 2-7). According to the most recent position statement by the American Society for Reproductive Medicine (ASRM), intracycle variation in AMH is considered minimal, and standardizing the timing of assessments is not a requirement at this time [48].

Five out of thirteen studies involving 210 obese and 550 non-obese women with regular menstrual cycles documented either significantly lower AMH levels in the obese compared to non-obese groups and/or a negative association between AMH and BMI. Percent differences in AMH levels between groups ranged from $-9.7 \%$ to $-76.7 \%$ (Mean: $-27.4 \%$; Median: $-21.8 \%$ ). The BMI of the non-obese participants ranged from 20.7 to $22.4 \mathrm{~kg} / \mathrm{m}^{2}$, and that of the obese participants ranged from 33.0 to $46.0 \mathrm{~kg} / \mathrm{m}^{2}$, which is consistent with the inclusion of women across Class $1\left(30\right.$ to $<35 \mathrm{~kg} / \mathrm{m}^{2}$ ), Class 2 (35 to $\left.<40 \mathrm{~kg} / \mathrm{m}^{2}\right)$, and Class $3\left(40 \mathrm{~kg} / \mathrm{m}^{2}\right.$ or higher) obesity—as well as a lack of any overweight individuals in the non-obese group. Studies were also conducted across a broad array of countries and included diverse ethnic populations from North America [46,47] and Europe $[44,45,49]$. Participants ranged in age from 23 to 46 years, with the mean age across studies being approximately 30 years. Studies were largely cross-sectional in nature and involved an assessment of serum AMH levels at a single time point during the menstrual cycle. Collectively, this group of studies included a similar number of obese women but more than double the number of non-obese women compared to the studies that reported no difference in AMH across BMI groups. A broader range of obesity was represented, but studies were more limited in their geographic representation. 
Table 1. Characteristics of studies reporting AMH levels in non-obese and obese reproductive-aged women with regular menstrual cycles.

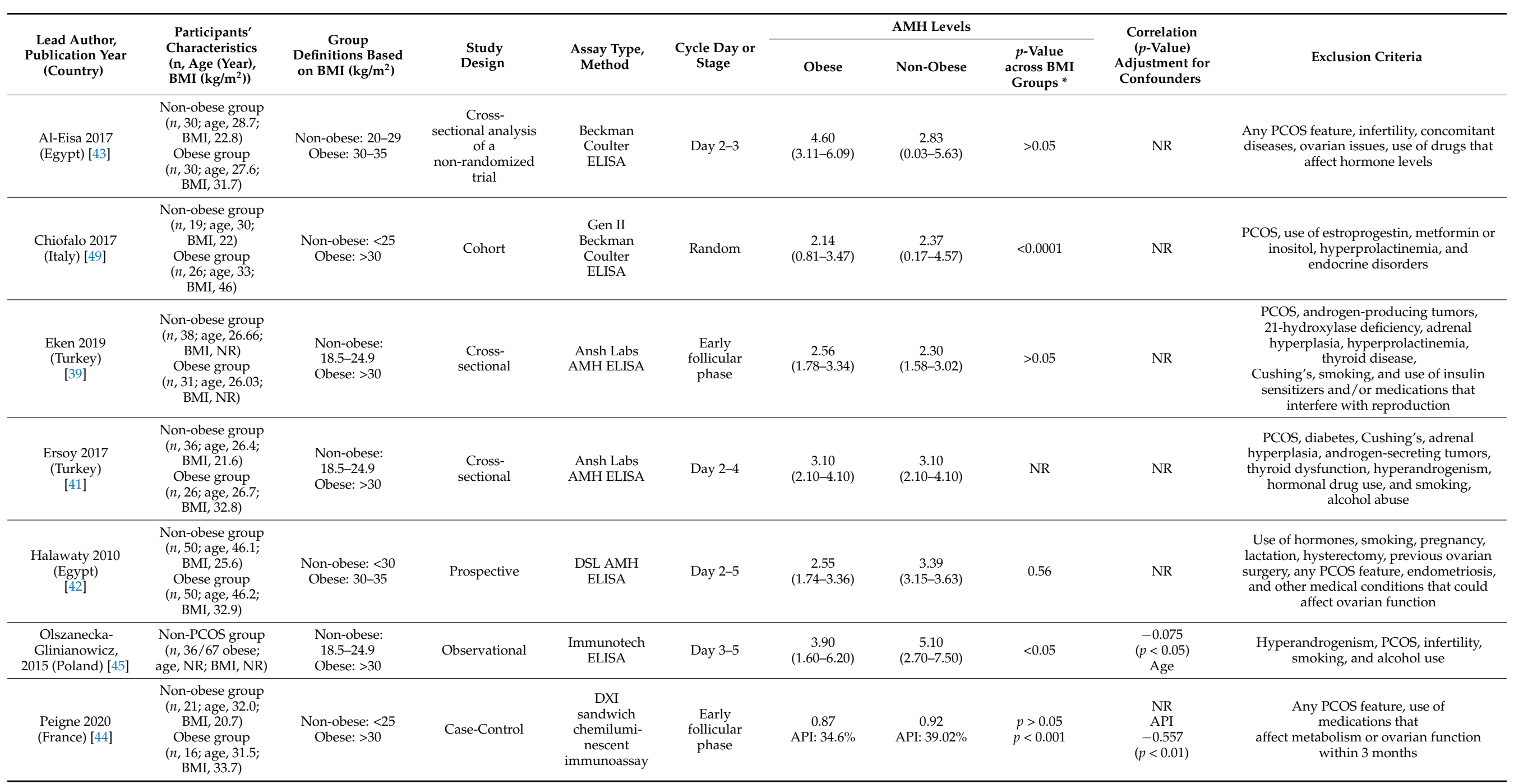


Table 1. Cont

\begin{tabular}{|c|c|c|c|c|c|c|c|c|c|c|}
\hline \multirow{2}{*}{$\begin{array}{l}\text { Lead Author, } \\
\text { Publication Year } \\
\text { (Country) }\end{array}$} & \multirow{2}{*}{$\begin{array}{l}\text { Participants' } \\
\text { Characteristics } \\
\text { (n, Age (Year), } \\
\left.\text { BMI }\left(\mathrm{kg} / \mathrm{m}^{2}\right)\right)\end{array}$} & \multirow{2}{*}{$\begin{array}{c}\text { Group } \\
\begin{array}{c}\text { Definitions Based } \\
\text { on BMI }\left(\mathrm{kg} / \mathrm{m}^{2}\right)\end{array}\end{array}$} & \multirow[b]{2}{*}{$\begin{array}{c}\text { Study } \\
\text { Design }\end{array}$} & \multirow[b]{2}{*}{$\begin{array}{l}\text { Assay Type, } \\
\text { Method }\end{array}$} & \multirow[b]{2}{*}{$\begin{array}{l}\text { Cycle Day or } \\
\text { Stage }\end{array}$} & \multicolumn{3}{|c|}{ AMH Levels } & \multirow{2}{*}{$\begin{array}{l}\text { Correlation } \\
(p \text {-Value) } \\
\text { Adjustment for } \\
\text { Confounders }\end{array}$} & \multirow[b]{2}{*}{ Exclusion Criteria } \\
\hline & & & & & & Obese & Non-Obese & $\begin{array}{c}p \text {-Value } \\
\text { across BMI } \\
\text { Groups * }\end{array}$ & & \\
\hline $\begin{array}{c}\text { Roth } 2014 \\
\text { (United States) } \\
\text { [37] }\end{array}$ & $\begin{array}{c}\text { Non-obese group } \\
(n, 10 ; \text { age, } 27.3 ; \\
\text { BMI, 22.3) } \\
\text { Obese group } \\
(n, 10 ; \text { age, 32.5; } \\
\text { BMI, 34.3) } \\
\end{array}$ & $\begin{array}{l}\text { Non-obese: } \\
18.5-25 \\
\text { Obese: }>30\end{array}$ & $\begin{array}{c}\text { Cross- } \\
\text { sectional }\end{array}$ & $\begin{array}{l}\text { Gen II } \\
\text { Beckman } \\
\text { Coulter } \\
\text { ELISA }\end{array}$ & Mid-cycle & $\begin{array}{c}0.02 \\
(0.01-0.06)\end{array}$ & $\begin{array}{c}0.05 \\
(0.02-0.10)\end{array}$ & 0.10 & NR & $\begin{array}{c}\text { Hyperandrogenism, chronic diseases, use } \\
\text { of exogenous sex steroids or medications } \\
\text { known to affect reproductive hormones, } \\
\text { regular exercise }>4 \text { h weekly, } \\
\text { or attempting } \\
\text { pregnancy }\end{array}$ \\
\hline $\begin{array}{c}\text { Shahin } 2020 \\
\text { (Jordan) } \\
\text { [40] }\end{array}$ & $\begin{array}{l}\text { Non-obese group } \\
\text { (NR) } \\
\text { Obese group } \\
\text { (NR) }\end{array}$ & $\begin{array}{l}\text { Non-obese: } \\
18.5-25 \\
\text { Obese: }>30\end{array}$ & Case-Control & $\begin{array}{l}\text { Roche Cobas } \\
\text { ECLIA }\end{array}$ & Day 2-4 & $3.11(0.92-5.3)$ & $\begin{array}{c}2.91 \\
(-0.16-5.98)\end{array}$ & 0.70 & NR & $\begin{array}{l}\text { PCOS, congenital adrenal hyperplasia, } \\
\text { Cushing's, malabsorptive or eating } \\
\text { disorders, menopause, history of } \\
\text { bariatric surgery }\end{array}$ \\
\hline $\begin{array}{c}\text { Shaw } 2011 \\
\text { (United States) } \\
\text { [36] }\end{array}$ & $\begin{array}{c}\text { Non-obese group } \\
(n, 31 ; \text { age, } 23.8 ; \\
\text { BMI, 22.2) } \\
\text { Obese group } \\
(n, 36 ; \text { age, } 27.3 ; \\
\text { BMI, 33.4) }\end{array}$ & $\begin{array}{l}\text { Non-obese: }<25 \\
\text { Obese: }>30\end{array}$ & Case-Control & $\begin{array}{l}\text { Beckman } \\
\text { Coulter } \\
\text { ELISA }\end{array}$ & Random & 0.64 & 0.61 & 0.76 & NR & Post-menopause, breast cancer \\
\hline $\begin{array}{c}\text { Steiner } 2017 \\
\text { (United States) } \\
\text { [46] }\end{array}$ & $\begin{array}{c}\text { Non-obese group } \\
\text { (n, } 461 ; \text { age, NR; } \\
\text { BMI, NR) } \\
\text { Obese group } \\
(n, 114 \text {; age, NR; } \\
\text { BMI, NR })\end{array}$ & $\begin{array}{l}\text { Non-obese: } \\
18.5-24.9 \\
\text { Obese: }>30\end{array}$ & Cohort & $\begin{array}{l}\text { Gen II } \\
\text { Beckman } \\
\text { Coulter } \\
\text { ELISA }\end{array}$ & Day 2-4 & $\begin{array}{c}2.20 \\
(0.90-4.00)\end{array}$ & $\begin{array}{c}2.85 \\
(1.50-5.50)\end{array}$ & 0.06 & NR & $\begin{array}{l}\text { Known fertility problems (sterilization, } \\
\text { PCOS, tubal blockage), endometriosis, } \\
\text { previous or current use of fertility } \\
\text { treatments, partner with a history of } \\
\text { infertility, lactation, recent use of } \\
\text { injectable hormonal } \\
\text { contraception }\end{array}$ \\
\hline $\begin{array}{c}\text { Su } 2008 \\
\text { (United States) } \\
{[47]}\end{array}$ & $\begin{array}{l}\text { Non-obese group } \\
(n, 18 ; \text {; age, } 45 ; \\
\text { BMI, 22.4) } \\
\text { Obese group } \\
(n, 18 ; \text { age, } 45.1 ; \\
\text { BMI, 37.6) }\end{array}$ & $\begin{array}{c}\text { Non-obese: }<25 \\
\text { Obese: }>30\end{array}$ & $\begin{array}{c}\text { Cross- } \\
\text { sectional }\end{array}$ & $\begin{array}{l}\text { DSL AMH } \\
\text { ELISA }\end{array}$ & Day 1-4 & $\begin{array}{c}0.07 \\
(0.03-0.15)\end{array}$ & $\begin{array}{c}0.30 \\
(0.14-0.63)\end{array}$ & 0.01 & $p=0.02$ & Hormonal therapy, contraception, PCOS \\
\hline $\begin{array}{l}\text { Woloszynek } 2015 \\
\text { (Brazil) } \\
\text { [38] }\end{array}$ & $\begin{array}{c}\text { Non-obese group } \\
\text { (n, 66; age, NR; } \\
\text { BMI, NR) } \\
\text { Obese group } \\
(n, 10 ; \text { age, NR; } \\
\text { BMI, NR) }\end{array}$ & $\begin{array}{c}\text { Non-obese: }<25 \\
\text { Obese: }>30\end{array}$ & $\begin{array}{c}\text { Cross- } \\
\text { sectional }\end{array}$ & $\begin{array}{l}\text { Gen II } \\
\text { Beckman } \\
\text { Coulter } \\
\text { ELISA }\end{array}$ & Day 2-7 & $\begin{array}{c}1.90 \\
(0.40-10.90)\end{array}$ & $\begin{array}{c}2.90 \\
(0.30-11.20)\end{array}$ & 0.29 & NR & $\begin{array}{l}\text { Chronic diseases, menstrual irregularity, } \\
\text { PCOS, infertility, hysterectomy, } \\
\text { oophorectomy, serum LH and FSH } \\
\text { concentrations out of the reference ranges }\end{array}$ \\
\hline
\end{tabular}

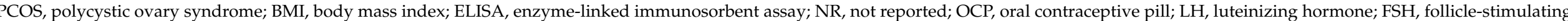

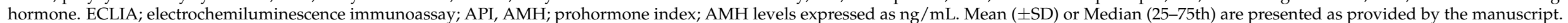

* Spearman's correlation is presented where available. 


\section{Discussion}

In the present work, we aimed to provide an updated review of whether obesity per se affects AMH production in healthy, potentially fertile women. Our study comprised a total of 13 studies involving 403 obese and 811 non-obese women, respectively. Overall, the data do not support a consistent impact of obesity on AMH levels in women with regular menstrual cycles. Specifically, of the 13 studies included in this review, only one was designed to evaluate the potential for differences in AMH levels between non-obese and obese women with regular menstrual cycles [42]. The remaining studies reported AMH levels for healthy non-obese and obese women with regular menstrual cycles as part of their (baseline) clinical characteristics for studies aimed at: (1) contrasting reproductive and metabolic features of women with or without PCOS [37,39-41,43-45,49], (2) predicting onset of menopause [17] or time to natural conception [26], or (3) assay validation and reference range development [38].

Our findings contrast those of Moslehi et al. [19], which is, to our knowledge, the only review exploring an impact of obesity on a broad array of ovarian reserve markers, including AMH. The authors showed lower AMH levels in obese women based on a pooled analysis involving 211 obese and 233 non-obese, fertile non-PCOS women (weighted mean differences, $-0.94,95 \% \mathrm{CI}-1.14,-0.73 \mathrm{ng} / \mathrm{mL}$ ) and a negative relationship between $\mathrm{AMH}$ and obesity [19]. Several reasons may have contributed to differences in the findings between Moslehi et al. and our current observations. Our approach to identifying relevant studies differed from that of Moslehi et al. in having used different definitions for nonobese and obese groups. We defined obesity as strictly being a BMI $>30 \mathrm{~kg} / \mathrm{m}^{2}$ as per the World Health Organization (WHO) definition [50], whereas obesity was defined using variable cut-offs by Moslehi et. al. Furthermore, we included overweight women in the lean group when available. This was in contrast to Moslehi et al., who included overweight women in the obese group. Our decision to pool overweight women into the non-obese group was consistent with the approach taken by two of the included studies $[42,43]$ and the observation that antral follicle dynamics and $\mathrm{AMH}$ production do not seem to be compromised during natural cycles in this population [51,52]. Most of the studies identified in our review $(11 / 13$ studies, $85 \%)$ [36,38-41,44-47,49,53] compared strictly obese $\left(\geq 30 \mathrm{~kg} / \mathrm{m}^{2}\right)$ versus lean $\left(<25 \mathrm{~kg} / \mathrm{m}^{2}\right)$ women, and only two studies [42,43] included overweight $\left(25-29.9 \mathrm{~kg} / \mathrm{m}^{2}\right)$ women, which were grouped into their non-obese cohorts. Therefore, there are few data on AMH levels in overweight women included in this review reflecting that there are very few data available in this population at large. Unlike Moslehi et al., we did not include women with sub-fertility and accounted for more recent studies, since their search was limited to those published by 2016 . Ultimately, we identified nearly twice as many studies (13 versus seven studies) that reported AMH levels in otherwise healthy reproductive-aged women with regular menstrual cycles, with a majority $(54 \%)$ being published after 2016. Therefore, there was only an overlap of three studies between our reviews. Moslehi et al. noted significant heterogeneity in AMH levels as part of their evidence synthesis [19]. Yet unlike Moslehi et al., we decided not to conduct a pooled analysis owing to high heterogeneity in AMH levels in the studies we identified, as well as the high degree of heterogeneity in the approaches employed by the various studies. This is consistent with a recent approach used by others in their evidence synthesis of AMH levels in women with PCOS wherein experts concluded that heterogeneity across studies would not enable any robust conclusions to be drawn on pooled analyses involving AMH [54].

\subsection{Most Studies Showed No Difference in AMH Levels with Obesity}

Included in this group of eight studies was the lone study whose primary aim was to evaluate differences in AMH levels between obese $(n=50)$ and non-obese $(n=50)$ groups. Mean AMH levels were 32.9\% lower in the obese group compared to the non-obese group, but differences did not reach statistical significance [42]. While this study used stringent criteria to corroborate the healthy reproductive status of the participants, Halawaty et al. used a narrow definition for obesity $\left(30-35 \mathrm{~kg} / \mathrm{m}^{2}\right)$, which primarily included women with 
Class 1 obesity. Furthermore, the mean and range of the BMI of the non-obese group were 25.6 and $24-29 \mathrm{~kg} / \mathrm{m}^{2}$, respectively, possibly indicating a small number of women with BMI $18.5-24.9 \mathrm{~kg} / \mathrm{m}^{2}$ in the lean group. Ultimately, the spectrum of adiposity in the study by Halawaty et al. may not have been sufficient to capture a significant effect of obesity on $\mathrm{AMH}$ production [42]. It must also be noted that this study focused on establishing an impact of obesity on the markers of ovarian reserve, specifically in older reproductive-aged women during the early transition phase of the late premenopausal state. As such, all women demonstrated regular menstrual cycle length (22-35 days) but also variability in cycle length by seven days in either direction for at least two cycles. The mean age of the non-obese and obese groups was 46.1 and 46.2 years and may not wholly reflect AMH production in younger women that are well outside the perimenopausal transition.

In a study by Woloszynek et al. involving 100 younger women with a mean age of 31, AMH levels were not significantly different across three BMI categories (lean, overweight, and obese) [38]. The study was designed to validate the use of the Gen II AMH immunoassay for use in reproductive-aged males and females and develop normative reference ranges for these populations. As secondary aims, any potential influence of hormonal contraceptives, smoking, and BMI on AMH levels was evaluated. Woloszynek et al. did not detect a significant association between $\mathrm{AMH}$ and $\mathrm{BMI}$ even after accounting for age in their analysis. This study involved a small number of women with a BMI textgreater $30 \mathrm{~kg} / \mathrm{m}^{2}$ $(\mathrm{n}=10)$, and the AMH values for this group were highly variable (95\% CI: $0.4-10.9 \mathrm{ng} / \mathrm{mL})$, which is in line with its minimal contribution to the pooled analysis. Furthermore, approximately $30 \%$ of all females included in the study used oral hormonal contraceptives $(\mathrm{OCP})$, albeit the degree to which the groups of interests were on OCP was not reported. The unbalanced representation of obesity in this cohort alongside any confounding effects of OCP use may have impacted the ability to detect an impact of obesity on AMH levels.

\subsection{Fewer Studies Showed Decreased AMH with Obesity}

Except for a single study [48], the remaining four studies included in this group were small, involving $\leq 50$ participants in both non-obese and obese cohorts combined. While women in the obese and non-obese groups across all these studies had comparable age distributions, the BMI classes of the groups were variable, especially in those with obesity, and none of the studies included women who were overweight. Of these, the studies by Chiofalo et al. [49] and Olszanecka-Glinianowicz et al. [45] showed significantly lower AMH levels in obese versus non-obese women, with AMH levels being 9.7\% $(p<0.0001)$ and $23.5 \%(p<0.01)$ lower, respectively. Furthermore, the study by OlszaneckaGlinianowicz et al. showed a negative correlation between AMH levels and BMI ( $r=-0.30$, $p<0001)$. Chiofalo et al. evaluated AMH levels as part of an intervention study involving bariatric surgery. As such, their obese group consisted of women with Class 3 obesity (mean BMI $=46 \mathrm{~kg} / \mathrm{m}^{2}$ ). In contrast, the study by Olszanecka-Glinianowicz et al. that investigated AMH levels in the context of largely Class 1 obesity. Overall, these results suggest that obesity may have a negative impact on AMH across the obesity spectrum with a dose effect that is not linear.

Furthermore, a small study $(n=36)$, Su et al. (2008) examined associations between obesity and serum and ultrasound measures of ovarian reserve in women of late reproductive age (mean age: 45 years) who did not use hormonal contraceptives or have PCOS [47]. AMH levels were a striking $76.7 \%$ lower in the obese cohort compared to the non-obese group $(p=0.014)$. The authors identified BMI as an independent predictor of $\mathrm{AMH}$ and concluded that lower AMH levels in obese women of late reproductive age resulted from physiologic processes other than a decreased ovarian reserve.

Of the studies with larger sample sizes, Steiner et al. reported a trend $(p=0.06)$ toward differences in AMH levels across BMI groups involving a total of 750 women in underweight, lean, overweight, and obese groups [46]. In the case of groups of interest to this review, AMH levels were $29.5 \%$ and $28.1 \%$ lower in 114 obese women with regular cycles and no history of infertility compared to 461 lean and 155 overweight women with 
similar reproductive health histories, respectively-which is consistent with AMH levels being quite similar in lean and overweight groups. The study was designed to assess any association between the biomarkers of ovarian reserve and time to natural conception in a group of late reproductive age women (30-44 years) in which rigorous approaches were used to exclude known fertility problems, ovaries disorders, and recent hormonal conception use. Ultimately, Steiner et al. adjusted their time to pregnancy models for AMH by BMI to reflect obesity as an important covariate.

\subsection{AMH Assay Variability as the Main Factor Contributing to Inconsistent Reports}

Differences in AMH levels between healthy women and women with subfertility have been well documented [22]. This difference is reflected in other markers of ovarian reserve, such as antral follicle counts [55]. Biological factors, including age, genetic variation within the AMH gene (i.e., $A M H$ and $A M H 2$ ) [56], race and ethnicity [57], and stage of the menstrual cycle [58] all have been posited to influence AMH production to varying degrees, with some factors garnering more support than others. By contrast, technical factors related to variability in AMH assay performance are an accepted contributor. In our review, seven different assays were used across the 13 included studies. Comparability studies have been performed between some of the assays used but given the large number of AMH assays on the market and the discontinuation of others, not all the assays represented in this review have been evaluated against each other for comparability. Namely, data are available to contrast the performance of the original Beckman Coulter ELISA, Beckman Coulter Gen II ELISA, Roche Elecys Cobas, and the Ansh ELISA. However, data are not available for the DSL ELISA, Immunotech ELISA, or DXI sandwich chemiluminescent immunoassay. Based on the available evidence, AMH levels measured by the different assays can vary drastically (up to 40\%) [59]. This appreciable sample-to-sample variability and the substantial discrepancies in the between-assay conversion factors that have been proposed suggest assay performance issues. Differential responses to pre-analytical proteolysis, conformational changes of the AMH dimer, or the presence of interfering substances are speculated to play a role [54]. To that end, Teede et al. recently called for an international reference standard for $\mathrm{AMH}$ and the more robust independent evaluation of commercial assays in routine use using clinical samples with well-defined sample handling and processing protocols [54].

\subsection{Other Factors Contributing to Inconsistent Reports}

This review centered on women with regular menstrual cycles. Yet, in line with some of the studies included in this review, we cannot exclude the possibility that some women may have had a mild variant of PCOS according to the Rotterdam criteria (i.e., hyperandrogenism and polycystic ovarian morphology). Eleven of the 13 studies identified in this review explicitly used a PCOS diagnosis as an exclusionary factor, and we were careful to exclude studies wherein subfertility or infertility were documented in the control group, which together make the inclusion of women with mild PCOS unlikely. That being said, inclusion of women with milder forms of PCOS could confound the interpretation of AMH levels given that AMH is known to be elevated in PCOS [24] - albeit a negative relationship between AMH and BMI has been observed in the context of PCOS [60]. Another important confounder is the use of hormonal contraceptives. Nine of the 13 studies excluded women using medications known to interfere with reproduction, such as oral contraceptive pills (OCP) or other forms of hormonal contraception. However, four studies made no mention of their use. Furthermore, of the nine studies that excluded for OCP use, they did so only in the context of recent use (i.e., in the last 2 months). Studies have shown that women on OCP or other hormonal contraceptives display lower AMH levels [61,62] with long-term users having 30\% lower AMH levels than non-users $[63,64]$. This is an important consideration in the context of this review, since hormonal contraception is known to have variable responses in obese populations [65]. Lastly, it is well documented that a history of smoking is associated with decreased AMH levels, with one study reporting up to a 4-fold decrease [61]. Only four of the papers included in the review specifically 
excluded women who were smokers. As such, any effect of smoking may be present in this analysis, confounding the impact of BMI on AMH. Future research should account for these important variables.

\section{Conclusions}

Collectively, the findings of this review do not corroborate a consistent negative impact of obesity on AMH. Our evaluation is consistent with most studies showing comparable $\mathrm{AMH}$ levels between obese and non-obese groups of reproductive-aged women with regular menstrual cycles, wherein women with obesity primarily presented with milder obesity status. Studies reporting AMH levels in otherwise healthy women are primarily limited by small sample size, cross-sectional design, and lack of representation across the entire adiposity spectrum - with an existing emphasis on lower obesity classes and absence of women who are overweight. Given that previous evidence supports that severe obesity may lower AMH levels and possibly ovarian reserve, it is critical to address this knowledge gap [27]. Few studies have prospectively evaluated the relationship between obesity and AMH production, and more mechanistic studies are needed to better understand how obesity and/or alterations in metabolic status could regulate $\mathrm{AMH}$. The inclusion of women across all BMI classes (including overweight and Class 1-3 obesity) should be prioritized in future research with larger samples sizes to ensure the generalizability of findings to all reproductive-aged women. Ultimately, the notion of a negative impact of obesity on AMH in healthy women with regular menstrual cycles may be deemed uncertain at this time-or at best limited to women with severe obesity, warranting further investigations to address the limitations of the current evidence. This conclusion is prudent in light of the biological basis for such an impact being largely unknown.

Author Contributions: Conceptualization, A.L.O. and M.K.; methodology, A.L.O. and M.K.; validation, A.L.O., M.K. and M.E.L.; formal analysis, A.L.O.; investigation, A.L.O.; resources, M.E.L.; writing-original draft preparation, A.L.O.; writing—review and editing, M.K. and M.E.L.; visualization, A.L.O. and M.K.; supervision, M.E.L.; project administration, A.L.O. and M.K. All authors have read and agreed to the published version of the manuscript.

Funding: This research was supported by the National Institutes of Health (R01HD093748).

Institutional Review Board Statement: Not applicable.

Informed Consent Statement: Not applicable.

Data Availability Statement: No new data were created or analyzed in this study. Data sharing is not applicable to this article.

Conflicts of Interest: The authors declare no conflict of interest.

\section{References}

1. Hales, C.; Carroll, M.; Fryar, C.; Ogden, C. Prevalence of Obesity and Severe Obesity Among Adults: United States, 2017-2018. In NCHS Data Brief; 2020; 360, pp. 1-8. Available online: https://www.cdc.gov/nchs/products/databriefs/db360.htm (accessed on 27 July 2020).

2. Aronne, L.J.; Nelinson, D.S.; Scientific, C.; Lillo, J.L.; Assistant, D.O. Obesity as a Disease State: A New Paradigm for Diagnosis and Treatment. Clin. Cornerstone 2009, 9, 9-29. [CrossRef]

3. Practice Committee of the American Society for Reproductive Medicine. Obesity and reproduction: A committee opinion. Fertil. Steril. 2015, 104, 1116-1126. [CrossRef] [PubMed]

4. Kazemi, M.; Jarrett, B.Y.; Van den Brink, H.; Lin, A.W.; Hoeger, K.M.; Spandorfer, S.D.; Lujan, M.E. Obesity, insulin resistance, and hyperandrogenism mediate the link between poor diet quality and ovarian dysmorphology in reproductive-aged women. Nutrients 2020, 12, 1953. [CrossRef] [PubMed]

5. Kyrou, I.; Randeva, H.S.; Tsigos, C.; Kaltsas, G.; Weickert, M.O. Clinical Problems Caused by Obesity. In Endotext; MDText.com, Inc.: South Dartmouth, MA, USA, 2000.

6. Klenov, V.E.; Jungheim, E.S. Obesity and reproductive function: A review of the evidence. Curr. Opin. Obstet. Gynecol. 2014, 26, 455-460. [CrossRef] [PubMed]

7. Practice Committee of the American Society for Reproductive Medicine. Obesity and reproduction: A committee opinion. Obes. Infertil. 2015, 104, 92027. 
8. Zhu, D.; Chung, H.F.; Pandeya, N.; Dobson, A.J.; Kuh, D.; Crawford, S.L.; Gold, E.B.; Avis, N.E.; Giles, G.G.; Bruinsma, F.; et al. Body mass index and age at natural menopause: An international pooled analysis of 11 prospective studies. Eur. J. Epidemiol. 2018, 33, 699-710. [CrossRef]

9. Silvestris, E.; de Pergola, G.; Rosania, R.; Loverro, G. Obesity as disruptor of the female fertility. Reprod. Biol. Endocrinol. 2018, 16, 22. [CrossRef]

10. Dă̆, Z.Ö.; Dilbaz, B. Impact of obesity on infertility in women. J. Turkish Ger. Gynecol. Assoc. 2015, 16, 111-117. [CrossRef]

11. Moy, V.; Jindal, S.; Lieman, H.; Buyuk, E. Obesity adversely affects serum anti-müllerian hormone (AMH) levels in Caucasian women. J. Assist. Reprod. Genet. 2015, 32, 1305-1311. [CrossRef]

12. Gesink Law, D.C.; Maclehose, R.F.; Longnecker, M.P. Obesity and time to pregnancy. Hum. Reprod. 2007, 22, 414-420. [CrossRef]

13. Van der Steeg, J.W.; Steures, P.; Eijkemans, M.J.C.; Habbema, J.D.F.; Hompes, P.G.A.; Burggraaff, J.M.; Oosterhuis, G.J.E.; Bossuyt, P.M.M.; Van der Veen, F.; Mol, B.W.J. Obesity affects spontaneous pregnancy chances in subfertile, ovulatory women. Hum. Reprod. 2008, 23, 324-328. [CrossRef]

14. Rich-Edwards, J.W.; Spiegelman, D.; Garland, M.; Hertzmark, E.; Hunter, D.J.; Colditz, G.A.; Willett, W.C.; Wand, H.; Manson, J.A.E. Physical activity, body mass index, and ovulatory disorder infertility. Epidemiology 2002, 13, 184-190. [CrossRef]

15. Fedorcsák, P.; Dale, P.O.; Storeng, R.; Ertzeid, G.; Bjercke, S.; Oldereid, N.; Omland, A.K.; Åbyholm, T.; Tanbo, T. Impact of overweight and underweight on assisted reproduction treatment. Hum. Reprod. 2004, 19, 2523-2528. [CrossRef] [PubMed]

16. De Pergola, G.; Maldera, S.; Tartagni, M.; Pannacciulli, N.; Loverro, G.; Giorgino, R. Inhibitory effect of obesity on gonadotropin, estradiol, and inhibin B levels in fertile women. Obesity 2006, 14, 1954-1960. [CrossRef]

17. Jain, A.; Polotsky, A.J.; Rochester, D.; Berga, S.L.; Loucks, T.; Zeitlian, G.; Gibbs, K.; Polotsky, H.N.; Feng, S.; Isaac, B.; et al. Pulsatile luteinizing hormone amplitude and progesterone metabolite excretion are reduced in obese women. J. Clin. Endocrinol. Metab. 2007, 92, 2468-2473. [CrossRef]

18. Robker, R.L.; Akison, L.K.; Bennett, B.D.; Thrupp, P.N.; Chura, L.R.; Russell, D.L.; Lane, M.; Norman, R.J. Obese women exhibit differences in ovarian metabolites, hormones, and gene expression compared with moderate-weight women. J. Clin. Endocrinol. Metab. 2009, 94, 1533-1540. [CrossRef]

19. Moslehi, N.; Shab-Bidar, S.; Ramezani Tehrani, F.; Mirmiran, P.; Azizi, F. Is ovarian reserve associated with body mass index and obesity in reproductive aged women? A meta-analysis. Menopause 2018, 25, 1046-1055. [CrossRef]

20. Almeida, F.R.C.L.; Costermans, N.G.J.; Soede, N.M.; Bunschoten, A.; Keijer, J.; Kemp, B.; Teerds, K.J. Presence of anti-Müllerian hormone (AMH) during follicular development in the porcine ovary. PLoS ONE 2018, 13, e0197894. [CrossRef] [PubMed]

21. Jeppesen, J.V.; Anderson, R.A.; Kelsey, T.W.; Christiansen, S.L.; Kristensen, S.G.; Jayaprakasan, K.; Raine-Fenning, N.; Campbell, B.K.; Yding Andersen, C. Which follicles make the most anti-Mü llerian hormone in humans? Evidence for an abrupt decline in AMH production at the time of follicle selection. Mol. Hum. Reprod. 2013, 19, 519-527. [CrossRef] [PubMed]

22. Dewailly, D.; Andersen, C.Y.; Balen, A.; Broekmans, F.; Dilaver, N.; Fanchin, R.; Griesinger, G.; Kelsey, T.W.; La Marca, A.; Lambalk, C.; et al. The physiology and clinical utility of anti-Müllerian hormone in women. Hum. Reprod. Update 2014, 20, 370-385. [CrossRef]

23. Zheng, H.; Liu, J.; Chen, S. Ovarian response prediction in controlled ovarian stimulation for IVF using anti-Müllerian hormone in Chinese women. Fertil. Steril. 2015, 104, e132-e133. [CrossRef]

24. Abbara, A.; Eng, P.C.; Phylactou, M.; Clarke, S.A.; Hunjan, T.; Roberts, R.; Vimalesvaran, S.; Christopoulos, G.; Islam, R.; Purugganan, K.; et al. Anti-müllerian hormone (AMH) in the diagnosis of menstrual disturbance due to polycystic ovarian syndrome. Front. Endocrinol. 2019, 10, 656. [CrossRef]

25. Kruszynska, A.; Slowinska-Srzednicka, J. Anti-Müllerian hormone (AMH) as a good predictor of time of menopause. Prz. Menopauzalny 2017, 16, 47-50. [CrossRef] [PubMed]

26. Steiner, A.Z.; Herring, A.H.; Kesner, J.S.; Meadows, J.W.; Stanczyk, F.Z.; Hoberman, S.; Baird, D.D. Antimüllerian Hormone as a Predictor of Natural Fecundability in Women Aged 30-42 Years Conclusions-Early-follicular phase antimüllerian hormone appears to be associated with natural fertility in the general population. Obs. Gynecol 2011, 117, 798-804. [CrossRef] [PubMed]

27. Jaswa, E.G.; Rios, J.S.; Cedars, M.I.; Santoro, N.F.; Pavone, M.E.G.; Legro, R.S.; Huddleston, H.G. Increased body mass index is associated with a nondilutional reduction in antimüllerian hormone. J. Clin. Endocrinol. Metab. 2020, 105, 3234-3242. [CrossRef] [PubMed]

28. Nardo, L.G.; Yates, A.P.; Roberts, S.A.; Pemberton, P.; Laing, I. The relationships between AMH, androgens, insulin resistance and basal ovarian follicular status in non-obese subfertile women with and without polycystic ovary syndrome. Hum. Reprod. 2009, 24, 2917-2923. [CrossRef]

29. Merhi, Z.; Buyuk, E.; Berger, D.S.; Zapantis, A.; Israel, D.D.; Chua, S.; Jindal, S. Leptin suppresses anti-Mullerian hormone gene expression through the JAK2/STAT3 pathway in luteinized granulosa cells of women undergoing IVF. Hum. Reprod. 2013, 28, 1661-1669. [CrossRef]

30. Griesinger, G.; Dafopoulos, K.; Buendgen, N.; Cascorbi, I.; Georgoulias, P.; Zavos, A.; Messini, C.I.; Messinis, I.E. Elimination half-life of anti-Müllerian hormone. J. Clin. Endocrinol. Metab. 2012, 97, 2160-2163. [CrossRef]

31. Nteeba, J.; Ganesan, S.; Keating, A.F. Progressive Obesity Alters Ovarian Folliculogenesis with Impacts on Pro-Inflammatory and Steroidogenic Signaling in Female Mice1. Biol. Reprod. 2014, 91, 86. [CrossRef]

32. Saxena, U.; Ramani, M.; Singh, P. Role of AMH as Diagnostic Tool for Polycystic Ovarian Syndrome. J. Obstet. Gynecol. India 2018, 68, 117-122. [CrossRef] [PubMed] 
33. Safdarian, L.; Attar, S.N.G.; Aleyasin, A.; Aghahosseini, M.; Sarfjoo, F.S.; Hosseinimousa, S. Investigation of anti-mullerian hormone $(\mathrm{AMH})$ level and ovarian response in infertile women with endometriosis in IVF cycles. Int. J. Reprod. Biomed. 2018, 16, 719-722. [PubMed]

34. Committee on Gynecologic Practice: The Use of Antimüllerian Hormone in Women Not Seeking Fertility Care. Obstet. Gynecol. 2019, 133, e274-e278. [CrossRef]

35. Meczekalski, B.; Czyzyk, A.; Kunicki, M.; Podfigurna-Stopa, A.; Plociennik, L.; Jakiel, G.; Maciejewska-Jeske, M.; Lukaszuk, K. Fertility in women of late reproductive age: The role of serum anti-Müllerian hormone (AMH) levels in its assessment. J. Endocrinol. Investig. 2016, 39, 1259-1265. [CrossRef]

36. Shaw, K.A. Serum antimüllerian hormone in healthy premenopausal women. Fertil. Steril. 2011, 95, 2718-2721. [CrossRef] [PubMed]

37. Roth, L.W.; Allshouse, A.A.; Bradshaw-Pierce, E.L.; Lesh, J.; Chosich, J.; Kohrt, W.; Bradford, A.P.; Polotsky, A.J.; Santoro, N. Luteal phase dynamics of follicle-stimulating and luteinizing hormones in obese and normal weight women. Clin. Endocrinol. 2014, 81, 418-425. [CrossRef]

38. Woloszynek, R.R.; Brito, L.P.; Batista, M.C.; Valassi, H.P.L.; Mendonca, B.B.; Brito, V.N. Validation of an immunoassay for anti-Müllerian hormone measurements and reference intervals in healthy Brazilian subjects. Ann. Clin. Biochem. 2015, 52, 67-75. [CrossRef]

39. Kurek Eken, M.; Sahin Ersoy, G.; Yayla Abide, C.; Sanverdi, İ.; Devranoglu, B.; Kutlu, T.; Çevik, Ö. Association between circulating neuregulin 4 levels and metabolic, aterogenic, and AMH profile of polycystic ovary syndrome. J. Obstet. Gynaecol. (Lahore) 2019, 39, 975-980. [CrossRef]

40. Shahin, L.; Hyassat, D.; Batieha, A.; Khader, Y.; El-Khateeb, M.; Ajlouni, K. Insulin Sensitivity Indices in Patients with Polycystic Ovary Syndrome with Different Body Mass Index Categories. Curr. Diabetes Rev. 2019, 16, 483-489. [CrossRef] [PubMed]

41. Sahin Ersoy, G.; Altun Ensari, T.; Vatansever, D.; Emirdar, V.; Cevik, O. Novel adipokines WISP1 and betatrophin in PCOS: Relationship to AMH levels, atherogenic and metabolic profile. Gynecol. Endocrinol. 2017, 33, 119-123. [CrossRef]

42. Halawaty, S.; ElKattan, E.; Azab, H.; ElGhamry, N.; Al-Inany, H. Effect of Obesity on Parameters of Ovarian Reserve in Premenopausal Women. J. Obstet. Gynaecol. Can. 2010, 32, 687-690. [CrossRef]

43. Al-Eisa, E.; Gabr, S.A.; Alghadir, A.H. Effects of supervised aerobic training on the levels of anti-mullerian hormone and adiposity measures in women with normo-ovulatory and polycystic ovary syndrome. J. Pak. Med. Assoc. 2017, 67, 499-507. [PubMed]

44. Peigné, M.; Pigny, P.; Pankhurst, M.W.; Drumez, E.; Loyens, A.; Dewailly, D.; Catteau-Jonard, S.; Giacobini, P. The proportion of cleaved anti-Müllerian hormone is higher in serum but not follicular fluid of obese women independently of polycystic ovary syndrome. Reprod. Biomed. Online 2020. [CrossRef]

45. Olszanecka-Glinianowicz, M.; Madej, P.; Owczarek, A.; Chudek, J.; Skałba, P. Circulating anti-Müllerian hormone levels in relation to nutritional status and selected adipokines levels in polycystic ovary syndrome. Clin. Endocrinol. 2015, 83, 98-104. [CrossRef]

46. Steiner, A.Z.; Pritchard, D.; Stanczyk, F.Z.; Kesner, J.S.; Meadows, J.W.; Herring, A.H.; Baird, D.D. Association between biomarkers of ovarian reserve and infertility among older women of reproductive age. J. Am. Med. Assoc. 2017, 318, 1367-1376. [CrossRef]

47. Su, H.I.; Sammel, M.D.; Freeman, E.W.; Lin, H.; Deblasis, T.; Gracia, C.R. Body size affects measures of ovarian reserve in late reproductive age women. Menopause 2008, 15, 857-861. [CrossRef] [PubMed]

48. Pfeifer, S.; Butts, S.; Dumesic, D.; Fossum, G.; Giudice, L.; Gracia, C.; La Barbera, A.; Odem, R.; Pisarska, M.; Rebar, R.; et al. Testing and interpreting measures of ovarian reserve: A committee opinion. Fertil. Steril. 2015, 103, e9-e17. [CrossRef]

49. Chiofalo, F.; Ciuoli, C.; Formichi, C.; Selmi, F.; Forleo, R.; Neri, O.; Vuolo, G.; Paffetti, P.; Pacini, F. Bariatric Surgery Reduces Serum Anti-mullerian Hormone Levels in Obese Women With and Without Polycystic Ovarian Syndrome. Obes. Surg. 2017, 27, 1750-1754. [CrossRef]

50. Vaamonde, J.G.; Álvarez-Món, M.A. Obesity and overweight. Medicine 2020, 13, 767-776. [CrossRef]

51. Vanden Brink, H.; Chizen, D.; Hale, G.; Baerwald, A. Age-related changes in major ovarian follicular wave dynamics during the human menstrual cycle. Menopause 2013, 20, 1243-1254. [CrossRef] [PubMed]

52. Robertson, D.M.; Lee, C.H.; Baerwald, A. Interrelationships among reproductive hormones and antral follicle count in human menstrual cycles. Endocr. Connect. 2016, 5, 98-107. [CrossRef] [PubMed]

53. Roth, L.W.; Bradshaw-Pierce, E.L.; Allshouse, A.A.; Lesh, J.; Chosich, J.; Bradford, A.P.; Polotsky, A.J.; Santoro, N. Evidence of GnRH antagonist escape in obese women. J. Clin. Endocrinol. Metab. 2014, 99, 871-875. [CrossRef]

54. Teede, H.J.; Misso, M.L.; Costello, M.F.; Dokras, A.; Laven, J.; Moran, L.; Piltonen, T.; Norman, R.J.; Andersen, M.; Azziz, R.; et al. Recommendations from the international evidence-based guideline for the assessment and management of polycystic ovary syndrome. Fertil. Steril. 2018, 110, 364-379. [CrossRef] [PubMed]

55. Deb, S.; Campbell, B.K.; Clewes, J.S.; Pincott-Allen, C.; Raine-Fenning, N.J. Intracycle variation in number of antral follicles stratified by size and in endocrine markers of ovarian reserve in women with normal ovulatory menstrual cycles. Ultrasound Obstet. Gynecol. 2013, 41, 216-222. [CrossRef] [PubMed]

56. Gorsic, L.K.; Dapas, M.; Legro, R.S.; Hayes, M.G.; Urbanek, M. Functional Genetic Variation in the Anti-Müllerian Hormone Pathway in Women with Polycystic Ovary Syndrome. J. Clin. Endocrinol. Metab. 2019, 104, 2855-2874. [CrossRef] 
57. Nelson, S.M.; Aijun, S.; Ling, Q.; Tengda, X.; Wei, X.; Yan, D.; Yanfang, W.; Zenghui, T.; Xinqi, C.; Fraser, A.; et al. Ethnic discordance in serum anti-Müllerian hormone in healthy women: A population study from China and Europe. Reprod. Biomed. Online 2020, 40, 461-467. [CrossRef] [PubMed]

58. La Marca, A.; Grisendi, V.; Griesinger, G. How much does AMH really vary in normal women? Int. J. Endocrinol. 2013, 2013. [CrossRef]

59. Melado, L.; Lawrenz, B.; Sibal, J.; Abu, E.; Coughlan, C.; Navarro, A.T.; Fatemi, H.M. Anti-müllerian Hormone During Natural Cycle Presents Significant Intra and Intercycle Variations When Measured With Fully Automated Assay. Front. Endocrinol. 2018, 9, 686. [CrossRef]

60. Feldman, R.A.; O’Neill, K.; Butts, S.F.; Dokras, A. Antimüllerian hormone levels and cardiometabolic risk in young women with polycystic ovary syndrome. Fertil. Steril. 2017, 107, 276-281. [CrossRef]

61. Dólleman, M.; Verschuren, W.M.M.; Eijkemans, M.J.C.; Dollé, M.E.T.; Jansen, E.H.J.M.; Broekmans, F.J.M.; Van der Schouw, Y.T. Reproductive and lifestyle determinants of anti-müllerian hormone in a large population-based study. J. Clin. Endocrinol. Metab. 2013, 98, 2106-2115. [CrossRef] [PubMed]

62. Hariton, E.; Shirazi, T.N.; Douglas, N.C.; Hershlag, A.; Briggs, S.F. Anti-Müllerian hormone levels among contraceptive users: Evidence from a cross-sectional cohort of 27,125 individuals. Am. J. Obstet. Gynecol. 2021. [CrossRef] [PubMed]

63. Bentzen, J.G.; Forman, J.L.; Pinborg, A.; Lidegaard, O.; Larsen, E.C.; Friis-Hansen, L.; Johannsen, T.H.; Nyboe Andersen, A. Ovarian reserve parameters: A comparison between users and non-users of hormonal contraception. Reprod. Biomed. Online 2012, 25, 612-619. [CrossRef] [PubMed]

64. Letourneau, J.M.; Cakmak, H.; Quinn, M.; Sinha, N.; Cedars, M.I.; Rosen, M.P. Long-term hormonal contraceptive use is associated with a reversible suppression of antral follicle count and a break from hormonal contraception may improve oocyte yield. $J$. Assist. Reprod. Genet. 2017, 34, 1137-1144. [CrossRef] [PubMed]

65. Shaw, K.A.; Edelman, A.B. Obesity and oral contraceptives: A clinician's guide. Best Pract. Res. Clin. Endocrinol. Metab. 2013, 27, 55-65. [CrossRef] [PubMed] 